\title{
CONTRIBUIÇÃO AO CONHECIMENTO DAS FASES IMATURAS DE OPHYRA AENESCENS (WIEDEMANN, 1830) E OPHYRA CHALCOGASTER (WIEDEMANN, 1824) (DIPTERA-MUSCIDAE)
}

\author{
Márcia Souto Couri ${ }^{1}$ \\ Paulo Francisco de Araújo ${ }^{1}$
}

\begin{abstract}
Descriptions and illustrations of external morphology of all immature phases of Ophyra aenescens (Wiedemann, 1830) and puparium of Ophyra chalcogaster (Wiedemann, 1824) are presented.
\end{abstract}

\section{INTRODUÇÃO}

A morfologia externa das fases jovens de $\mathbf{0}$. aenescens $e$ O. chalcogaster estả descrita em SKIDMORE (1985). O acompanhamento em laboratório do ciclo evolutivo de O. aenescens propiciou a observação de caracteres que complementam esta descrição, $o$ mesmo acontecendo com o pupário de 0 . chalcogaster.

\section{MÁTERIAL E MÉTODOS}

Os adultos foram coletados em Rocha Miranda, Rio de Janeiro (armadilhas do tipo utilizadas por FERREIRA (1978) e LINHARES (1981)), transportados para o laboratório de Diptera-Múscidae do Museu Nacional, onde se deu a criação. As colônias foram mantidas em vidros de boca larga (10 $\mathrm{cm}$ de diâmetro), com um saco plástico transparente preso à abertura. Peixe e solução de sacarose foram oferecidos como dieta. Os ovos obtidos e fragmentos de peixe foram transferidos para tubos de ensaio com um saco plástico preso à abertura. A partir da eclosão, foram realizadas observações a cada 4 horas durante os dois primeiros dias (eclosão do ovo e larva do primeiro instar), a cada 12 horas durante o terceiro e quarto dias (larva do segundo e terceiro ínstares) e diariamente, daí até a emergência. Exemplares de formas jovens foram retirados em cada uma das observações para acompanhamento do desenvolvimento.

A pouca disponibilidade de material de $O$. chalcogaster associada a dificuldade encontrada na criação desta espécie, permitiu apenas o estudo da morfologia do pupário.

O material estudado encontra-se depositado na coleção de Diptera-Muscidae do Museu Nacional, Rio de Janeiro.

\section{Ophyra aenescens}

OVO (Figs. 1.e 2): aspecto geral fig. 1; comprimento $(0,90-1,10 \mathrm{~mm})$ coloração branco leitosa, córion ornamentado com padrão hexagonal (Fig. 2) e faixas paralelas longitudinais em todo o seu comprimento. 
LARVA DO 10 INSTAR (Figs. 3-5): aspecto geral, fig. 3; comprimento 1,00-2,00 mm segmento cefálico com espinhos ventrais; segmento protorácico com espinhos curtos na metade basal, segmento meso e metatorácico sem espinhos, segmentos abdominais com espinhos ventrais; esqueleto cefalofaringeano com comprimento $0,29-0,33 \mathrm{~mm}$, corno dorsal mais longo que o ventral e com extremidade apical arredondada e larga, gancho bucal alongado e estreito (Fig. 4); espiráculo anterior ausente, espiráculo posterior terminal, levemente voltado para face dorsal, com fenda espiracular circular (Fig. 5).

LARVA DO 20. INSTAR (Figs. 6-9): aspecto geral, fig. 6; comprimento 2,80-6,00 mm; segmento cefálico com espinhos mais desenvolvidos que a larva do 1 . instar, segmento protorácico com espinhos ocupando toda a metade basal, segmentos mesotorácico, metatorácico e abdominais com espinhos ventrais e dorsais nos limites dos segmentos; esqueleto cefalofaringeano com comprimento $0,40-0,50 \mathrm{~mm}$, arco dorsal com uma leve elevação, mandíbula fina e alongada (Fig. 7); espiráculo anterior com sete projeções digitiformes localizado no $1^{0}$. segmento torácico (Fig. 8); espiráculo posterior com duas fendas transversais (Fig. 9).

LARVA DO 3. INSTAR (Figs. 10-12): aspecto geral, fig. 10, comprimento 6,50$11,00 \mathrm{~mm}$, limites de todos os segmentos com seis fileiras irregulares de espinhos, oitavo segmento abdominal com espinhos de distribuições irregulares mais concentrados na face ventral. Os espinhos da face ventral dos segmentos são os mais desenvolvidos; esqueleto cefalofaringeano com comprimento $0,60-1,10 \mathrm{~mm}$, corno dorsal mais largo e mais longo que o corno ventral (Fig. 11), gancho bucal levemente inclinado para baixo; espiráculo anterior como na larva do $2 \%$ instar; espiráculo posterior com três fendas transversais (Fig. 12).

PUPÄRlO (Fig. 13-17): aspecto geral, figs. 13 (dorsal) e 14 (ventral); comprimento 5,00-6,00 mm, coloração castanho escura; espiráculo anterior protuberante; corno respiratório localizado no limite inferior do terceiro segmento torácico medindo 0,30 . $0,40 \mathrm{~mm}$ (Fig. 15); região peri-anal com espinhos curtos e largos, fenda anal com abertura longitudinal com reentrâncias, ocupando quase todo o comprimento da parte mediana da placa, papila pós-anal cerca da metade do diâmetro das papilas sub-anais (Fig. 16); padrão do tegumento do último segmento em vista dorsal, como na fig. 17. Fendas espiraculares posteriores como na larva do 3 ? instar.

CONSIDERAÇŌES: Ophyra aenescens visita a armadilha a partir do $3^{\circ}$ ou $4^{\circ}$ dia, quando o grau de putrefação da isca está bem avançado. Durante o acompanhamento do trabalho foram observados os seguintes períodos de desenvolvimento: ovo - 0,5 dia; larva do primeiro instar - 0,5 dia; larva do segundo instar - 1,0 dia; larva do terceiro instar - 7,0/9,0 dias; pupa - 7,0/9,0 dias, perfazendo um total oviposição/adulto de 16 a 20 dias.

\section{Ophyra chalcogaster}

PUPÁRIO (Figs. 18-22): aspecto geral, figs. 18 (dorsal) e 19 (ventral); comprimento $5,00-6,50 \mathrm{~mm}$, coloração castanho escura, espiráculo anterior protuberante; corno respiratório como em Ophyra aenescens, região peri-anal e placa anal com espinhos curtos e largos, papilas pós-anal cerca de $1 / 4$ do diâmetro das papilas sub-anais; placa anal larga, ocupando toda a largura do segmento no qual se localiza (Fig. 20). Padrão do tegumento do último segmento em vista dorsal como na fig. 21. Fendas do espiráculo posterior levemente divergentes (Fig. 22). 


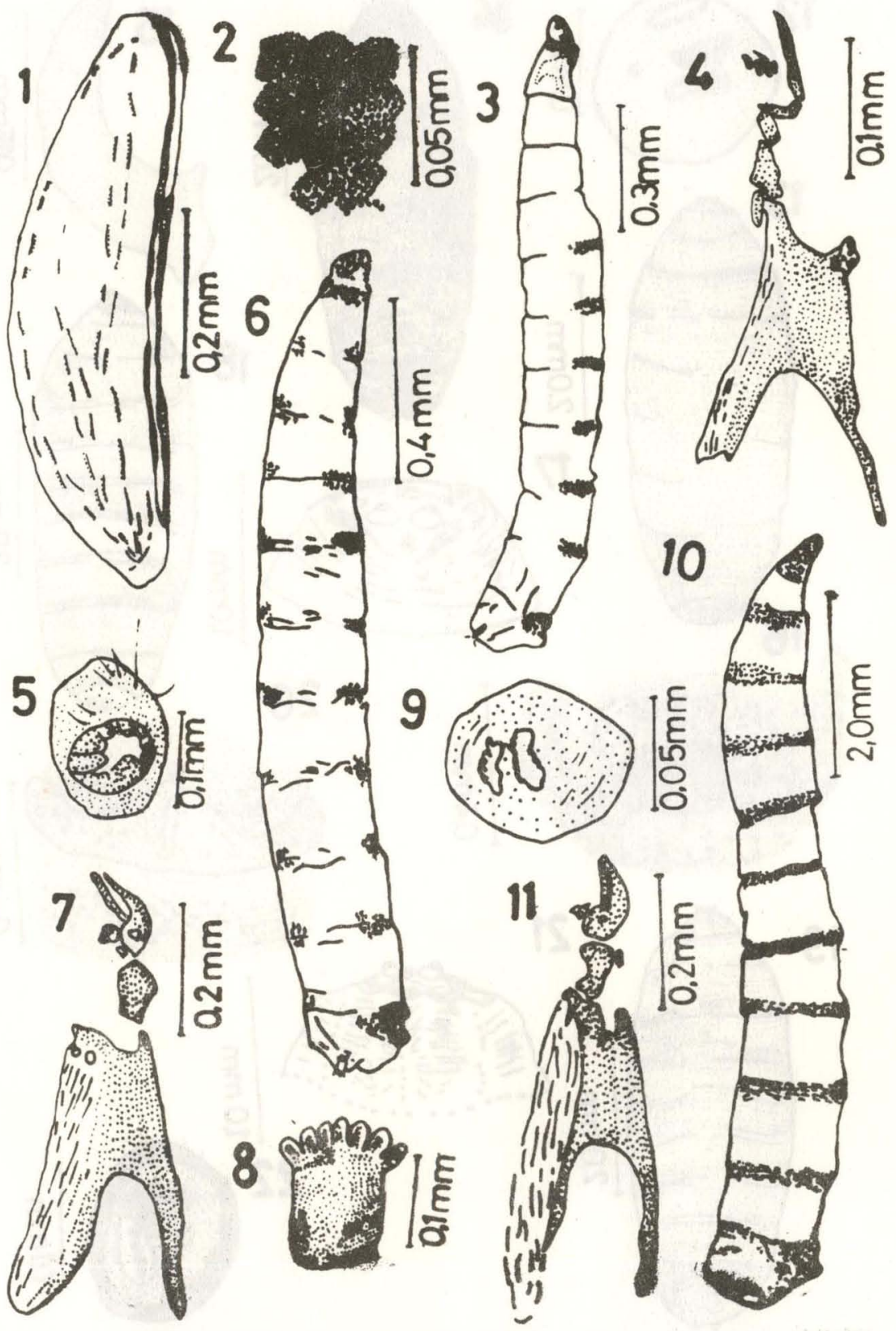

Figuras 1-11 - OVO - 1. aspecto geral, vista lateral; 2. padrão do córion. LARVA DO $1^{\circ}$ INSTAR 3. aspecto geral, vista lateral; 4. esqueleto cefalofaringeano; 5 . espiráculo posterior. LARVA DO 20 INSTAR - 6. aspecto geral, vista lateral; 7. esqueleto cefalofaringeano; 8. espiráculo anterior; 9. espiráculo posterior. LARVA DO $3^{\circ}$ INSTAR - 10. aspecto geral, vista lateral; 11. esqueleto cefalofaringeano. 
Revta bras. Zool.
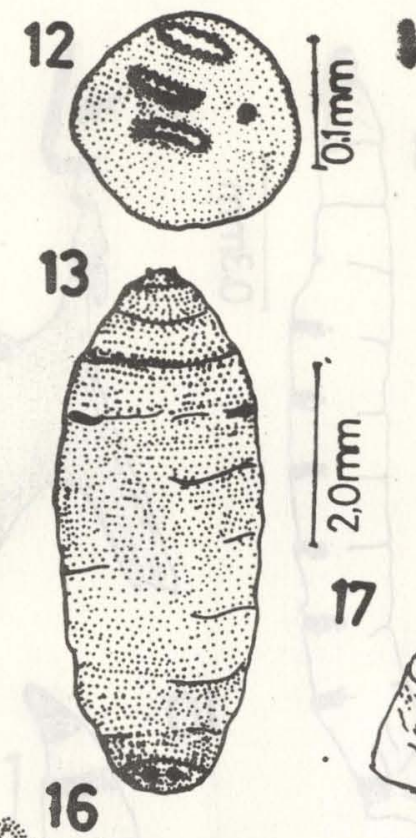

1
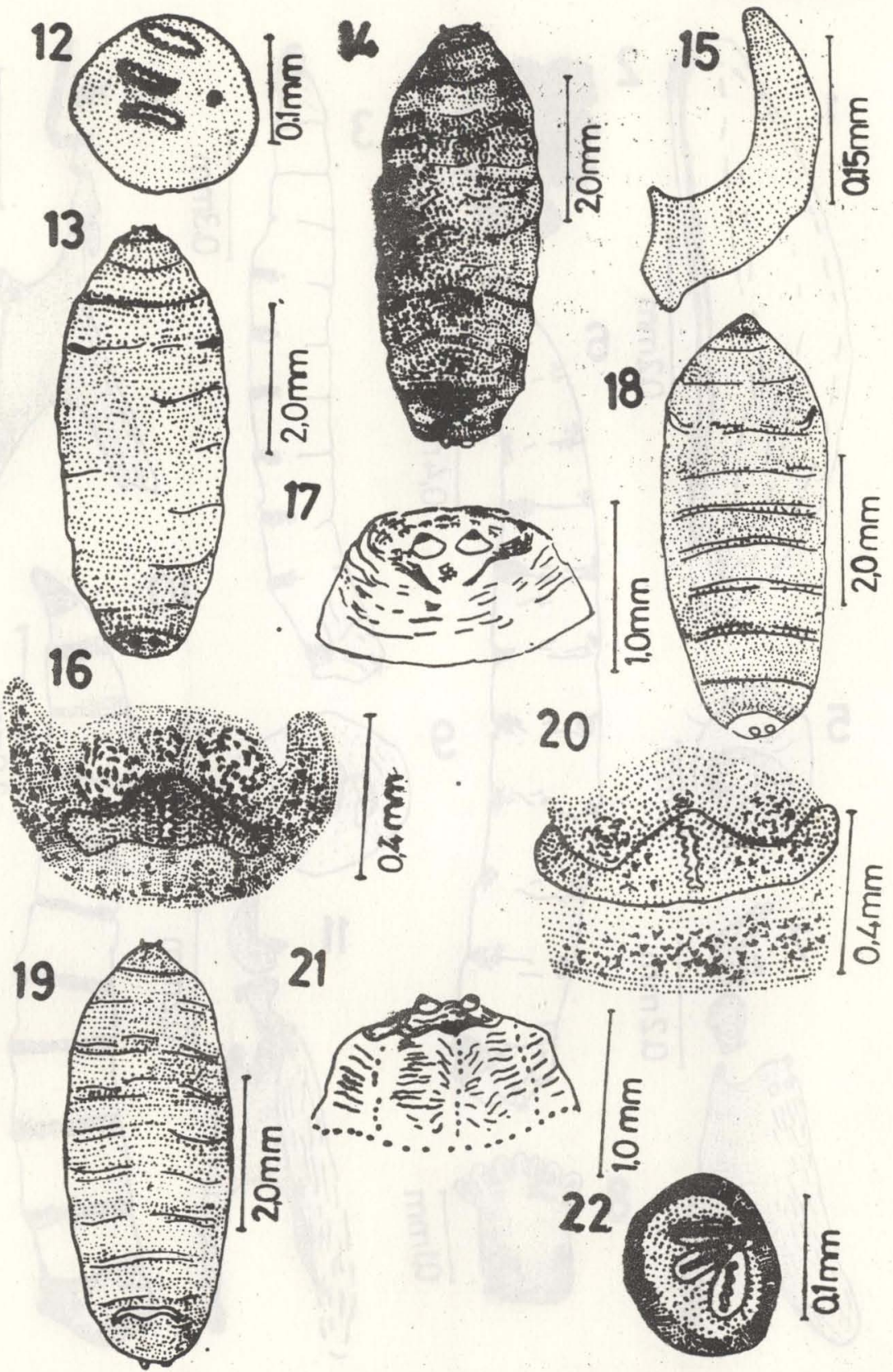

21

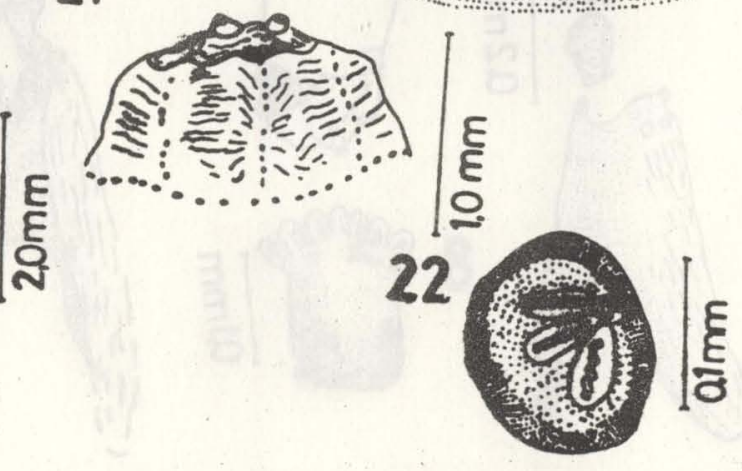

Figuraso12-22 - LARVA DO $3^{\circ}$ INSTAR - 12. espiráculo posterior. PUPÁRIO - 13. aspecto geral,

- vista dorsal; 14. aspecto geral, vista ventral; 15 . corno respiratório; 16. regióes anal e peri-anal; 17. padrão do tegumento do último segmento, vista dorsal; Ophyre chalcogaster; 18. aspecto geral, vista dorsal; 19. aspecto geral, vista ventral; 20. regiōes anal e peri-anal; 21. padrăo do tegumento do último segmento, vista dorsal; 22 . fenda do espiráculo posterior. 


\section{DISCUSSÃO}

$O$. aenescens e $O$. chalcogaster podem ser segrégadas pela forma da placa anal, diâmetros das papilas e pela direção das fendas do espiráculo posterior do pupário. SKIDMORE (1985) descreve as fases jovens de mais três espécies de Ophyra - O ignava (Harris), $O$. spinigera Stein e $O$. capensis (Wiedemann), esta última com distribuição geográfica ampla, abrangendo a região neotropical.

A chave abaixo auxilia na segregação das três espécies neotropicais com pupário conhecido:

1. Placa anal 'larga, ocupando toda a extensão do segmento onde se localiza, fendas espiraculares posteriores convergindo para o botão espiracular . . . . O. chalcogaster

1. Placa anal não ocupando toda a extensão do segmento onde se localiza; fendas espiraculares posteriores quase paralelas . . . . . . . . . . . . . 2

2. Projeções laterais da placa anal estreitas, papilas sub-anais de tamanho moderado . . . . . capensis

2'. Projeções laterais da placa anal largas, papilas sub-anais grandes, cerca do dobro do

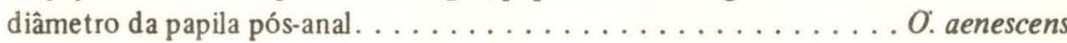

\section{REFERENCIAS}

FERREIRA, M.J.M., 1978. Sinantropia de dípteros muscóideos de Curitiba, Paraná. I. Calliphoridae. Revta bras. Biol., 38(2):445-454.

LINHARES, A.X. 1981. Synantropy of Calliphoridae and Sarcophagidae (Diptera) in the city of Campinas, São Paulo, Brazil. Revta bras. Ent., 35(3):189-215,

SKIDMORE, P., 1985. The biology of the Muscidae of the world. Drodrecht Junk Publishers, xiv $+550 \mathrm{pp}$. 